\title{
Entre universidade e sociedade, há espaço para a televisão
}

\author{
Alzimar Rodrigues Ramalho
}

\section{Resumo:}

A pesquisa tem como foco a necessidade de institucionalização das TVs, pois a principal hipótese é de que seu reconhecimento como mídia universitária é fundamental para que o segmento possa consolidar-se. A pesquisa justifica-se por contribuir com a reflexão sobre a relação entre a universidade enquanto produtora de conhecimento científico e a "sua" televisão, enquanto mídia educativa. Por meio desse veículo, a academia tem a possibilidade de estabelecer um diálogo com a comunidade.

\section{Palavras Chave:}

Televisão universitária; difusão científica; ensino; pesquisa; extensão.

\begin{abstract}
:
The research focus on the need to insert an university channel as part of the university's structure. Our hypothesis is that the channel recognition is considered crucial to its consolidation. The research contributes to the discussion on the relationship between the university, the producer of scientific knowledge, and the university channel, an educative media. Through this medium, the academia can establish a dialogue with the community.
\end{abstract}

\section{Keywords:}

University channel; scientific diffusion; teaching; research; extension.

O segmento universitário foi o precursor do modelo brasileiro de televisão pública quando em 1968 a Universidade Federal de Pernambuco obteve a concessão de um canal educativo, criando a TV Universitária de Recife. Até 1995, cerca de 15 instituições de ensino superior tinham outorgas de canais educativos abertos, com abrangência estadual e tendo como base de programação as duas grandes redes nacionais educativas de São Paulo e do Rio de Janeiro. Paralelamente, as universidades iniciavam suas produções audiovisuais, de caráter pedagógico e institucional. Naquele ano, com a promulgação da Lei 8.977/95 (Cabodifusão) foram instituídos os "Canais básicos de utilização gratuita" no sistema de televisão por assinatura, sendo utilizados por emissoras legislativas, universitárias e comunitárias, e a do Poder Judiciário desde 2002 (1).

Mesmo com acesso restrito ao cabo, em 2008 estima-se que o número de emissoras mantidas Instituições de Ensino Superior (IES) seja próximo de 100. Foi um importante espaço para uma produção que estreitou o vínculo dessas instituições com as realidades locais. Considerando que no Brasil cerca de $70 \%$ da pesquisa científica são provenientes de Instituições de Ensino Superior, especialmente as universidades públicas, é responsabilidade destes organismos compartilhar o conhecimento com a sociedade que os financiam por meio de impostos deiretos e indiretos. E a televisão, por estar presente em $98 \%$ dos lares brasileiros e alcançar uma audiência média de 18,4 horas por semana, é o veículo de divulgação científica por excelência.

A televisão "da" universidade deve estar baseada no tripé do ensino superior: ensino, pesquisa e extensão. No 
ensino, a participação acadêmica se dá na produção de conteúdo; na pesquisa, pelas possibilidades de experimentação no campo da comunicação e do desenvolvimento tecnológico; e na extensão, ao estabelecer um vínculo direto com a comunidade. Sendo uma mídia institucional, a TV Universitária não deve ser confundida com laboratório de aulas práticas da área de Comunicação Social, embora cumpra o papel de servir de suporte pedagógico pelo qual os estudantes vivenciam a cultura da produção audiovisual em um ambiente de ação-reflexão que propicia um ambiente de maturidade profissional e pessoal. Esses pressupostos são identificados como "vocação e missão do veículo", de acordo com a Associação Brasileira de TVs Universitárias:

um ambiente privilegiado para a reflexão crítica (...) reafirmando seu compromisso com a produção de conteúdo voltado para educação, promoção da cultura e do desenvolvimento regional, constituindo-se também num espaço para pesquisa e experimentação de novas linguagens, formatos e narrativas, além de contribuir criticamente para a formação de um novo profissional de Comunicação (ABTU, 2004, p.1).

Esta pesquisa dá seqüência à dissertação de mestrado intitulada "A TV Universitária como ponte entre a produção científica e as massas: A TV FEMA de Assis - SP" (2005), que localiza a TV Universitária no "campo público"e apresenta suas especificidades quanto à missão, ética e seu papel na divulgação científica enquanto mídia educativa e cultural. No doutorado, iniciado em fevereiro de 2006, o foco está na necessidade de institucionalização das TVs, pois a principal hipótese é de que seu reconhecimento como mídia universitária é fundamental para que o segmento possa consolidar-se.

Uma pesquisa de campo está sendo realizada desde agosto de 2008 com as quase 2.500 IES registradas no site do Ministério da Educação, e o cronograma prevê que até dezembro de 2009 seja delineado o perfil das TVs Universitárias brasileiras quanto à sua gestão, conteúdo e envolvimento da comunidade acadêmica. Esses resultados vão embasar nossos pressupostos quanto à natureza desse veículo de comunicação de massa, pensado e produzido pela academia. Em fevereiro de 2009, terá início a etapa da pesquisa qualitativa, que vai abranger as seguintes televisões paulistas: TV USP (Universidade de São Paulo) e TV Unicsul (Universidade Cruzeiro do Sul). A coleta de dados será por meio de entrevistas com os gestores dessas instituições e das emissoras, assim como pela técnica de observação não participante. Esta pesquisa, enfim, dispõe-se a refletir sobre a relação da universidade enquanto produtora de conhecimento científico para com a "sua" televisão, enquanto mídia educativa.

Por meio desse veículo, a academia tem a possibilidade de estabelecer um diálogo com a comunidade e, enquanto instrumento pedagógico, promover um ambiente permanente de ação-reflexão, propiciado pela pesquisa. Apesar das suas potencialidades, as TVs Universitárias têm um espaço ainda a ser conquistado junto à comunidade científica, que historicamente não reconhece as mídias eletrônicas de massa como espaço de diálogo, haja vista a tradição do suporte impresso, com ênfase nas revistas científicas, em detrimento de outros veículos de comunicação. Um espaço de constantes questionamentos e desafios, que também possibilita a formação de profissionais críticos, conscientes, capazes de atuar significativamente, interferindo e contribuindo para o desenvolvimento da sociedade de que fazem parte.

\section{O campo público da televisão brasileira}

Conhecemos o Brasil que é mostrado pela TV; mas por qual modelo? Ao contrário da Europa e dos Estados Unidos, onde a TV nasceu pública, no Brasil, desde sua implantação na década de 1950, sempre esteve pautada sob a égide do mercado, na qual o valor da publicidade não está na qualidade do conteúdo, mas nos índices de audiência, que alcançam 98\% dos lares brasileiros. A implantação da TV Digital no Brasil está promovendo não apenas mudanças tecnológicas e de infra-estrutura no sistema de comunicação de massa, como também vem promovendo a discussão sobre o caráter público da televisão enquanto serviço público. 
O processo de migração tecnológica vem possibilitando a construção do "campo público de televisão" que deve ocupar a faixa que compreende os canais 60 a 69. São as emissoras educativo-culturais, universitárias, comunitárias e legislativas, além dos canais estatais, dos poderes Executivo, Legislativo e Judiciário. A consolidação dos propósitos do segmento público depende de seu reconhecimento nas respectivas instâncias de poder, e que usufrua do direito de exibição em rede aberta, cumprindo assim seu papel na complementaridade dos sistemas privado, público e estatal, prevista pela Constituição Federal (2).

Priolli (3) elenca as contribuições que as universidades podem dar nesse processo de migração digital:

A TV Digital traz pelo menos três vantagens em relação à TV convencional, analógica: 1) a multiplicação do número de canais, que pode significar maior democratização no acesso de atores sociais à tela; 2) a transmissão em alta-definição, que praticamente eliminará a distância técnica; 3) a interatividade, pela qual o telespectador poderá ter um papel ativo na produção e difusão de conteúdos. As emissoras universitárias, pela proximidade e ligação com os projetos de pesquisa universitários, poderá ser um campo privilegiado de provas, para experimentos em todas essas direções citadas. Particularmente quanto à interatividade, podemos trabalhar para desenvolver softwares e metodologias de uso da TV Digital pelos cidadãos, contribuindo para promover uma audiência de TV muito mais qualificada, exigente e ativa do que a existente hoje.

Omar Rincón (2002, p. 31-32), considerando o contexto de toda a América Latina, pontua cinco eixos que a serem considerados: 1) conceito é pautado na democracia, cidadania e visibilidade de atores sociais, embora "pouco ou nada se fala do que é propriamente televisivo, da linguagem audiovisual, dos gêneros e discursos que esse tipo de televisão deveria mostrar e experimentar"; 2) deve ter autonomia com relação ao governo e aos outros poderes instituídos, e ser o "lugar de realização de projetos de comunicação pluralista, diversa e de qualidade"; 3) consumidor e cidadão: "uma vez que todo telespectador é cidadão (...) o horizonte do sentido é a formação do cidadão"; 4) legitimação social atribuída ao projeto pelos públicos (pelas audiências) quando os programas provocam o diálogo entre proposta criativa (produtores) e recepção social (públicos que assistem); e um quinto item que reforça o anterior pela importância de sua comunicabilidade: 5) possibilidades de televisão pública da América Latina (...) uma vez que é inútil fazer televisão se esta não é assistida pelas pessoas (grifos nossos).

Esses eixos revelam a demanda de todo o campo público e, especialmente nas TVs universitárias, contribuem para nortear o complexo processo de ação-reflexão do qual se constitui a televisão do ensino superior. Além de analisar o modelo estabelecido e fazer proposituras não apenas nos formatos (conceito), como nas relações institucionais com suas instituições mantenedoras.

\section{A lógica da audiência}

O baixo índice de audiência das emissoras públicas que merece atenção. Apesar da grande audiência das TVs comerciais, as educativo-culturais que também operam em canal aberto alcançam índices máximos de 5\%, enquanto as veiculadas no sistema por assinatura não passam de 3\% (4). Mesmo diametralmente oposta aos índices alcançados pelas grandes redes comerciais, os índices de audiência da TV Pública representam uma comunicação estabelecida com algumas milhares de pessoas. E, dada a presença da televisão no cotidiano do brasileiro, considerada por muitos como "avassaladora", Machado reforça:

A mais baixa audiência de televisão é, ainda assim, uma audiência de várias centenas de milhares de telespectadores e, portanto, muito superior à mais massiva audiência de qualquer outro meio, equivalente à performance comercial de um best seller na área da literatura. Esta é, talvez, a contribuição mais importante da televisão para a superação da incômoda equação "melhor 
repertório/menor audiência': agora, mesmo a menor audiência é sempre a maior que um trabalho de alta qualidade poderia almejar. Esse simples fato já não justifica toda a televisão?” (2001, p. 30).

Essa visibilidade tende a ser aumentada com a implantação da TV Digital em todo o território nacional, prevista pelo Governo Federal para completar-se em 2018, que irá tornar acessíveis em canal aberto não apenas as TVs educativas estaduais, como hoje, mas todo o campo público, que deve ocupar a faixa que compreende os canais 60 a 69. Com isso, a TV Pública brasileira poderá alcançar uma visibilidade que demandará, por parte de seus produtores e gestores, uma reavaliação sobre seu papel enquanto sistema complementar aos modelos privado e estatal. Especificamente sobre as TVs Universitárias, Priolli (2006) considera a permanência no sistema de TVs por assinatura como uma contradição:

oferecemos, com grande saber, educação e cultura através de um sistema de transmissão que chega aos telespectadores exatamente com mais alto poder aquisitivo, e com certo grau de educação e informação. Claro que a educação no país, nós entendemos, deve ser um processo permanente, mas temos certeza de que teríamos uma utilidade muito maior, no sentido social do nosso trabalho, se pudéssemos falar para a grande massa telespectadora e oferecer a ela o conteúdo universitário.

Martin-Barbero e Rey (2001, p. 71) sugerem como desafio a esse campo a oferta de outros âmbitos de ficção e imaginação, outras possibilidades de compreensão do mundo cotidiano, outras maneiras de confrontar publicamente os temas de interesse dos cidadãos. E Citando Umberto Eco, eles alertam para a importância do público segmentado. "Canais e programas criam audiências-modelo que são muito mais do que espectadores fortuitos. Trata-se de grupos ou tribos identificáveis tanto por suas preferências midiáticas como por suas decisões vitais".

É necessário, portanto, que a TV pública brasileira saiba "com quem" vai se comunicar, para então definir "como" irá formatar sua programação. Na TV aberta, além da qualidade técnica que deverá ser compatível com a tecnologia utilizada pelas emissoras comerciais, as públicas terão como desafio conquistar uma audiência que, até então, desconhece sua própria existência enquanto alternativa de conteúdo, quanto mais seu direito a uma programação complementar aos modelos privado e estatal.

\section{A TV Universitária no Brasil}

As emissoras universitárias estão presentes em cerca de 100 Instituições de Ensino Superior, com maior incidência nas regiões Sudeste e Sul. De acordo com o jornalista Gabriel Priolli (2006) (5), a TVU procura mostrar o que é a universidade, o que faz a universidade e como pensa os diversos problemas da nossa realidade. É voltada para o público em geral, e para a comunidade universitária em particular.

Segundo dados de dezembro de 2006 (6), existem no Brasil 52 canais propriamente universitários, na TV a cabo, sendo alguns compartilhados por diversas universidades, agregando 90 instituições de ensino superior. Treze canais comerciais também inserem programas universitários, totalizando 65 canais no país oferecendo programação universitária. São 103 instituições fazendo televisão regularmente e quatro operando canais na internet, englobando 6\% do total de Instituições de Ensino Superior existentes. Considerando o número de cidades atingidas, e que algumas universidades utilizam-se de mais de um canal (a cabo e eventualmente na internet) 54 cidades brasileiras têm acesso à programação de canais universitários, com forte concentração nas regiões Sul e Sudeste, assim distribuídos: Região Norte 4; Nordeste 6, Centro-oeste 4, Sul 18 e Sudeste 22. Dois terços desses canais estão no sistema de Cabodifusão, e um terço na Radiodifusão (VHF e UHF).

Um problema estrutural do segmento universitário é sua precária institucionalização que, como descreve Priolli, "ainda não foi efetivamente metabolizada pelos organismos universitários e, em muitos casos, não constam ao menos no plano de cargos e salários dessas instituições". Para ele, essa situação prejudica o 
equilíbrio dos canais universitários, que devem representar os vários tipos de universidade. E desafia: "qual o espaço que podemos ocupar, de forma efetiva, num sistema de televisão educativa que possa atender todas as diversas demandas educacionais que existem - formação básica, ensino médio e cursos profissionalizantes? Somos uma segmentação da própria televisão educativa".

Duas possibilidades tecnológicas do Sistema Brasileiro de Televisão Digital Terrestre (SBTVD-T) são fundamentais para que o segmento possa cumprir sua missão: multiprogramação e interatividade. Desde o início das discussões sobre a migração digital, as TVs comerciais têm se posicionado contra a multiprogramação por entenderem que resultaria em uma grande dispersão de canais e, portanto, dos investimentos publicitários. A TV pública, ao contrário, vê nesse recurso a possibilidade de acomodar os diversos canais que hoje não estão presentes na TV aberta, ampliando as perspectivas de uma audiência mais massiva. A interatividade é um instrumento essencial a qualquer TV educativa, e pesquisas já vêm sendo realizadas para que essa ferramenta possa ser útil no processo de ensino-aprendizagem, que é a base de qualquer processo educacional.

\section{A relação da TVU com a comunidade}

O sistema verticalizado de televisão, no qual determinada emissora é a "cabeça" da rede, centraliza a produção e distancia o telespectador, já que o espaço para a produção local é praticamente nulo, e a programação regional normalmente resume-se ao telejornal ou a uma revista eletrônica, ainda assim com impacto maior nas cidades-sede das retransmissoras ou afiliadas dessas redes. Já a TV Universitária, por estar atrelada às operadoras de TV por assinatura, transmite sua programação em âmbito municipal, concretizando o relacionamento da universidade com a comunidade, dando vazão às suas demandas mais amplas.

As temáticas dos programas são ligadas a educação e cultura, e os gêneros mais utilizados são os discursivos (entrevistas, debates, palestras), algumas revistas jornalísticas e documentários já com presença razoavelmente significativa. Programas de entretenimento, e de ficção são exibidos em menor escala, pela carência de recursos técnicos e de pessoal exigido nesses formatos. As formas de participação acadêmica na produção de conteúdo são bastante variadas. Há canais nos quais a programação é totalmente feita por estudantes e professores, em outros essa participação é extremamente limitada, com produção terceirizada ou de responsabilidade de profissionais contratados para tal finalidade.

Grande parte das TVs está apoiada nos cursos de Comunicação, ou na reitoria ou nas mantenedoras. É um instrumento laboratorial de grande importância, não só para os estudantes como pesquisadores e professores, mas deve ser o canal da universidade, e claro que os cursos de comunicação devem ter o protagonismo dentro deles, e é importante que eles batalhem por isso, mas com a visão universal, com a visão da universidade, de todas as áreas do conhecimento.

\section{Gestão das TVs Universitárias}

Segundo dados da ABTU, o movimento financeiro dos 42 canais associados é de R $\$ 20$ milhões/ano, e estimase que o setor concentre cerca de $\mathrm{R} \$ 50$ milhões/ano.De modo geral há uma grande variação no orçamento das emissoras universitárias, tendo um custo anual médio de $\mathrm{R} \$ 500$ mil. A maior parte do financiamento vem das universidades, responsáveis por $84 \%$ - em média - do orçamento dos projetos além de patrocínio e apoio cultural e da prestação de serviço, na produção de conteúdos audiovisuais para terceiros. E, finalmente, pela publicidade comercial, mas em participação minoritária na receita de algumas emissoras.

Do ponto de vista da gestão, as TVs Universitárias são de modo geral constituídas por núcleos vinculados a faculdades de Comunicação Social ou departamentos de jornalismo ou de TV, outras são ligadas a núcleos de assessoria de comunicação institucional ou diretamente às reitorias e/ou mantenedoras. Todas, de modo geral, 
têm uma grande dificuldade de provimento de programação em decorrência da falta de captação de recursos, já que o investimento por parte das universidades, embora muitas sejam de grande porte, é inferior aos seus elevados custos de manutenção.

Para fazer frente a esses problemas, as TVs universitárias - assim com o todo o campo público - defendem uma mudança na legislação que defina critérios para que possam captar recursos junto à iniciativa privada, "desde que não seja a fonte majoritária das receitas, sob o risco de o canal começar a operar a partir de uma lógica comercial, que tem implicações óbvias sobre a programação”, alerta Priolli (idem). O segmento também aponta como alternativa de financiamento a participação das TVUs no planejamento de mídia dos governos federal, estadual ou municipal, assim como de autarquias e empresas estatais.

\section{Compartilhamento de conteúdo e infra-estrutura}

Por meio de convênio, a ABTU e a RNP (Rede Nacional de Pesquisa) desenvolveram um sistema de compartilhamento de programação que deverá fortalecer os canais universitários. A Rede de Intercâmbio de TVs Universitárias (RITU [7]), em operação experimental desde 2007, é uma interface web criada pelo LaViD/UFPB (8) - Laboratório de Aplicações de Vídeo Digital da Universidade Federal da Paraíba. Por meio da internet de banda larga, as TVs podem trocar seus conteúdos para retransmissão em seus canais, diferenciando-se do modelo atual por sua horizontalidade, que traz como vantagem a reciprocidade. Com total liberdade de escolha, as TVs armazenam em seus servidores os programas de interesse, podendo utilizá-los sem a determinação verticalizada de horários, fixados pelas "cabeças de rede". A emissora pode inclusive editar os programas, utilizando o conteúdo de acordo com as suas necessidades. Como destaca Adriano Adoryan, "há a criação de uma identidade universitária de TV nacional, mas com todo o respeito às demandas e peculiaridades locais". E o telespectador pode ter acesso a uma programação educativa do ensino superior, tendo acesso ao conhecimento científico e à produção tecnológica nos âmbitos do ensino, da pesquisa e da extensão. Esse modelo serve de base para o projeto ITVp, da EBC (Empresa Brasileira de Comunicação), cuja interface fornecerá meios para que todo o campo público troque conteúdo.

\section{Considerações finais}

Boas intenções não faltam nas discussões que a sociedade civil e o Governo estão promovendo para a consolidação do campo público de televisão. Em Maio de 2009 deve ocorrer o II Fórum Brasileiro de TVs Públicas, desta vez sendo realizado pelas entidades que representam os vários segmentos (o anterior, em 2007, teve iniciativa do Governo Federal). Com a migração digital, as emissoras públicas ainda lutam pelo direito à presença no canal aberto. Após 20 anos de promulgação da Constituição Federal, esse momento de mobilização desse segmento chama a atenção para a regulamentação das ações que implicam na complementaridade dos segmentos comercial, público e estatal.

As emissoras universitárias têm um obstáculo a mais para superar: conquistar o reconhecimento da sua própria comunidade. Fazer TV na Universidade é um desafio, pois além de ser tratada como um apêndice de cursos de comunicação ou como instrumento de marketing institucional, seu papel de ponte para a transmissão do conhecimento científico para a sociedade muitas vezes nem é reconhecido.

Espera-se que a possibilidade de ter o conteúdo universitário disponibilizado em rede aberta sirva de alerta para uma mudança de paradigmas nessa relação de desprezo ou estranhamento, e que a linguagem audiovisual seja reconhecida como auxiliar no processo de construção e transmissão do conhecimento. E que, finalmente, seja reconhecida e utilizada como um espaço de maturidade para a pesquisa e a experimentação. A TV Universitária tem todas as condições de oferecer uma programação de qualidade, alternativa e complementar aos outros modos de fazer televisão. E é isso que o telespectador espera. Essa deve ser a contribuição da Academia na pesquisa em Comunicação. 


\section{Bibliografia:}

BUCCI, Eugênio (org.). A TV aos 50: criticando a televisão brasileira no seu cinqüentenário. São Paulo: Fundação Perseu Abramo, 2000.

CARMONA, B. \& FLORA, M. (et al.). O desafio da TV pública: uma reflexão sobre sustentabilidade e qualidade. Rio de Janeiro: ACERP/TVE Rede Brasil, 2003.

FISCHER, R. M. B. Televisão e educação: fruir e pensar a TV. Belo Horizonte: Autêntica, 2003.

FÓRUM NACIONAL DE TVS PÚBLICAS, 2007, Brasília. Caderno de Debates: Diagnóstico do Campo Público de Televisão (texto de vários autores). Brasília: Ministério da Cultura, 2006. Vol. 1, 112p.

KUNSCH, M.; DENCKER, A. (orgs.). Produção Científica Brasileira em Comunicação na década de 1980: análises, tendências, perspectivas. São Paulo: Edicon, 1997.

LOPES, D. F. Jornal-laboratório. São Paulo: Summus, 1989.

LOPES, M. I. V. Pesquisa em comunicação. $6^{\text {a }}$ ed. São Paulo, Loyola, 2001.

MACHADO, A. A televisão levada a sério. $2^{\mathrm{a}}$ ed. São Paulo: Editora Senac, 2001.

MAGALHÃES, C. Manual para uma TV Universitária. Belo Horizonte: Autêntica, 2002.

MORAIS, C. (org.). Jornalismo científico e educação para as ciências. Taubaté: Cabral Editora e Livraria Universitária, 2006.

RAMALHO, A. A TV Universitária como ponte entre a produção científica e as massas: a TV Fema de Assis - SP. Marília, 2005. Dissertação de mestrado (mimeo.).

RINCON, O. (org.). Televisão Pública: do consumidor ao cidadão. São Paulo: SSRG, 2002.

TVE REDE BRASIL. O desafio da TV Pública, uma reflexão sobre sustentabilidade e qualidade. Rio de Janeiro. ACERP, 2003.

\section{Notas:}

(1) Lei 10.461, de 17 de maio de 2002, que modificou a Lei 8.977.

(2) Artigo 223.

(3) Entrevista publicada em www.abtu.org.br. Acesso em 10 de maio 2007.

(4) Dados apresentados pelo representante da Abepec no I Fórum Brasileiro de TVs Pùblicas. Brasília, maio de 2006. 
(5) Dados apresentados pela ABTU no I Fórum Brasileiro de TVs Públicas. Brasília, maio de 2006.

(6) Caderno de Debates do I Fórum Brasileiro de TVs Públicas, cujos dados estão sendo atualizados nesta pesquisa.

(7) http://www.abtu.org.br/ritu.

(8) http://www.lavid.ufpb.br.

\section{Mini Currículo :}

Jornalista, coordenadora do curso de Jornalismo da Fundação Educacional do Município de Assis e diretora geral da TV FEMA. Mestre em Comunicação: Mídia e Cultura pela Universidade de Marilia SP, doutoranda em Ciências da Comunicação pela ECA/USP e coordenadora científica da Associação Brasileira de TVs Universitárias (ABTU). 